\title{
Technology for Care Networks of Elders
}

\author{
Computer-supported coordinated care uses technology to aid the \\ network of people who support an elder living at home. CSCC supports \\ improved communication among individuals and a balanced \\ distribution of responsibilities to allow the elder to live at home despite \\ increasing care needs.
}

Sunny Consolvo, Peter Roessler, Brett E. Shelton, Anthony LaMarca, and Bill Schilit

Intel Research Seattle

Sara Bly

Sara Bly Consulting hances are that in your lifetime, you will both care for an elder and be cared for as an elder. Many people who are not professional caregivers are involved in caring for an elder, particularly when the elder lives at home. The potentially demanding responsibilities involved in that care affect the lives of these people.

We performed a user study that initially focused on developing information systems to reduce stress for elders' caregivers and concerned family members. Although we expected to find several people providing care and having concern for the elder, we were surprised at the broad range of people involved in the care and the extent to which caring for the elder affected their personal lives. We observed uneven distribution of responsibility, miscommunication, misunderstanding, distrust, unmet care needs, and negative impact on the careers and personal needs of the individuals involved. These issues were largely due to problems of coordinating the elder's care.

Technology can help people coordinate these activities. However, no one has thoroughly analyzed eldercare from the entire support network's viewpoint. For example, current research typically investigates how robots, smart phones, and so on can assist elders in their daily activities and how monitoring devices such as smart medicine cabinets ${ }^{1}$ can provide information to a caregiver (see the "Related Work in Eldercare Technologies" sidebar). Addressing specific issues in eldercare rather than issues of caring as a whole limits these technologies' impact in real-world deployments.

\section{Computer-supported coordinated care}

The problem of coordinating the care of elders living at home hasn't been well defined or explored. Our work focuses on using technology to aid the elder's entire support network. To distinguish this space from the broader research issues of computer-supported cooperative work, we call it computer-supported coordinated care and propose that it is a meaningful focus for the pervasive computing, CSCW, and human-computer interaction (HCI) communities.

Although some aspects of CSCC are very similar to existing CSCW work (activity theory, for example ${ }^{2}$ ), CSCC focuses on a person rather than a shared objective, such as "keeping a person healthy." This shift in focus has implications for supporting technology because issues such as emotion, trust, and privacy become foremost in importance. Although one of the support network's objectives is to keep the person healthy, it must also consider the person's mental and emotional states and overall well-being. In many circumstances, the network is dealing with a person who is slowly losing his or her independence.

\section{User studies}

To explore the space of eldercare, we con- 


\section{Related Work in Eldercare Technologies}

C omputer-supported coordinated care (CSCC) systems could use much of the work done by researchers who are exploring eldercare, where numerous efforts are ongoing. Several projects attempt to help elders maintain their independence, predominantly in the home environment. These efforts aim to directly assist elders, their caregivers, or their family members. For example, ethnographic research conducted by Intel on elders living with cognitive decline highlights the value of ubiquitous computing technologies to elder well being. ${ }^{1}$ William Mann and Sumi Helal are working on applications involving elders using smart phones to control their environment. ${ }^{2}$ The Digital Family Portraits project envisions a digital picture frame, augmented with information about an elder, being used by geographically distant extended-family members to provide peace of mind. ${ }^{3}$ The Nursebot project uses a robot at a retirement community to remind elders about routine activities and guide them through their environments. ${ }^{4}$

Other recent efforts are creating smart homes (homes instrumented with a variety of sensors and actuators) to help elders age in place - that is, remain in their homes as long as possible, postponing the transition to a care facility. For example, the Smart Medical Home at the University of Rochester includes prototype systems such as an interactive medical advisor. Other well-known homes include Georgia Tech's Aware Home and MIT's House_n. A similar project-Honeywell's Independent LifeStyle Assistantfocuses on using similar technology in existing homes.

CSCC systems could use the technology being developed for these homes to provide updates and communicate needs to the care network. For example, smart home sensors could report that the elder has taken morning medications, that the lawn needs mowing, or that the light bulb in the foyer needs to be replaced.

Observations from the Elder Project ${ }^{5}$ are directly relevant to CSCC. For example, Tad Hirsch and colleagues note that "the goals of healthcare change as patients age." They also claim that "opportunities exist for communication and technology products and applications to enhance communication between stakeholderselders, friends and family members, doctors and nurses." Despite this suggestion, they did not create any technology to support this idea, nor carry out studies to validate it. Our studies confirm the importance of the care network and use the results to establish the CSCC perspective.

\section{REFERENCES}

1. M. Morris et al., "New Perspectives on Ubiquitous Computing from Ethnographic Study of Elders with Cognitive Decline," Proc. 5th Int'I Conf. Ubiquitous Computing (UbiComp 2003), Springer-Verlag, 2003, pp. 227-241.

2. W. Mann and S. Helal, "Smart Phones for the Elders: Boosting the Intelligence of Smart Homes," Proc. AAAI Workshop Automation as Caregiver: The Role of Intelligent Technology in Elder Care, AAAI Press, 2002, pp. 74-79.

3. E.D. Mynatt et al., "Digital Family Portraits: Supporting Peace of Mind for Extended Family Members," Proc. Conf. Human Factors in Computing Systems, ACM Press, 2001, pp. 333-340.

4. M.E. Pollack et al., "Pearl: A Mobile Robotic Assistant for the Elderly," Proc. AAAI Workshop Automation as Eldercare, AAAI Press.

5. T. Hirsch et al., "The Elder Project: Social, Emotional, \& Environmental Factors in the Design of Eldercare Technologies," Proc. Conf. Universal Usability, ACM Press, 2000, pp. 72-79. ducted a series of interviews. More specifically, we sought to determine who was involved in the care, what types of care were needed, and what types of care were being provided. Within the support networks, we investigated communication methods and content. We further explored CSCC from multiple perspectives within the support network by addressing

- Roles within networks

- Communication structures within networks

- Types of information shared

- Importance of shared information

- Individuals' comfort in sharing information
We applied what we learned to the design of a technology probe-the CareNet Display (see the related sidebar for a summary). We deployed the CareNet Display with several support networks in an in situ study.

\section{Interviews}

From March to May 2003 we conducted a series of interviews with elders and their caregivers. ${ }^{3}$ We used semistructured interviews and a two-week phone diary study to uncover their current practices, needs, and privacy concerns. The data consisted of questionnaires, audio recordings, and investigator notes. The research team recruited all participants (we use pseudonyms throughout the article to protect participants' identities) through talks at local geriatric care meetings, posters in senior centers, and through work with domain experts. Interview participants were three elders (aged 83-93), four concerned family members (aged 51-65), three familial caregivers (aged 51-80), three professional caregivers (aged 31-70), and three geriatric care managers (aged 46-50).

We conducted the interviews, which ran from 60 to 90 minutes each, at the participant's preferred location: our offices, the participant's home, a senior center, or by phone (for nonlocal participants). Three of the four concerned family members participated in the follow- 


\section{CareNet Display}

$\mathrm{T}$ he CareNet Display is our initial technology probe in the space of computer-supported coordinated care. The CareNet Display is an interactive, ambient picture frame that augments digital photographs of elders with information about their daily lives; it was inspired by the Digital Family Portrait project. ${ }^{1}$ However, where the Digital Family Portrait targets distant family members to give them peace of mind, the CareNet Display targets local members of an elder's care network to help them coordinate care-related activities and disseminate information. Because our target user is different, our design differs from the Digital Family Portrait in terms of types of information and levels of detail. Figure A shows the CareNet Display technology probe, which includes a photograph of an elder surrounded by icons of specific events about her day: meals, medications, outings, activities, mood, falls, and calendar. To get details, the user touches an icon, which replaces the photo with details about that event. The display is automatically updated throughout the day.

The actual technology probe uses a touch-screen tablet PC housed in a custom-built beech wood frame.

Figure A. CareNet Display technology probe. The user can click any icon surrounding the elder's photo to get detailed information about an event. Icons represent meals, medications, outings, activities, mood, falls, and a calendar.

\section{REFERENCE}

1. E.D. Mynatt et al., "Digital Family Portraits: Supporting Peace of Mind for Extended Family Members," Proc. Conf. Human Factors in Computing Systems, ACM Press, 2001, pp. 333-340.

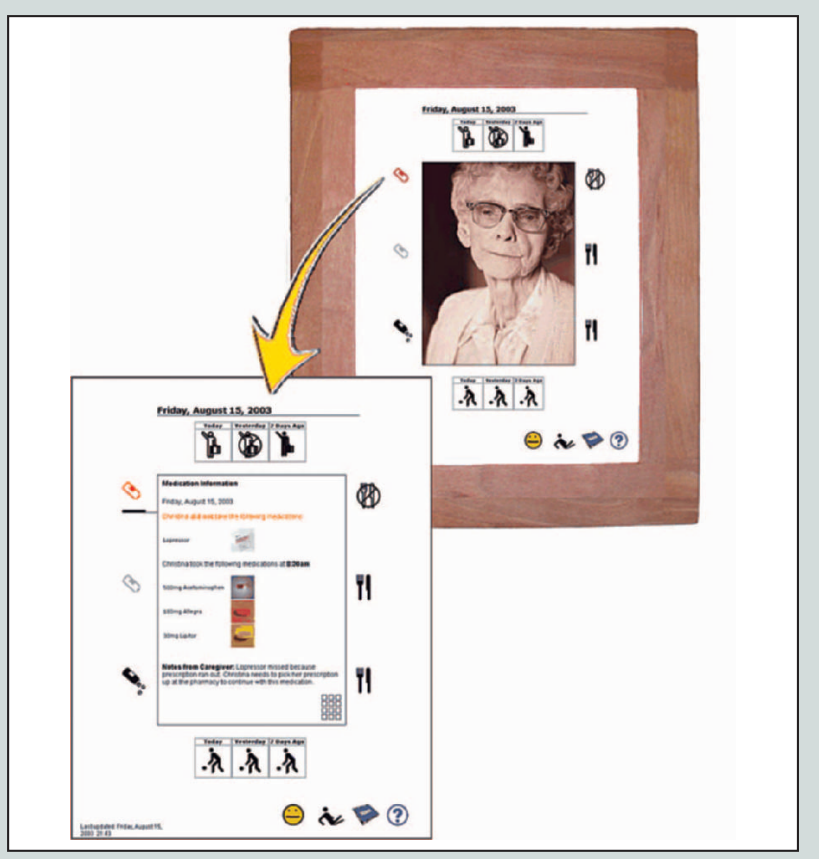

up phone diary study to further explore their daily care-related activities.

\section{In-home technology probe deployment}

In Fall 2003 we built and deployed the CareNet Display to investigate how sensor-based pervasive technologies might address the needs of support networks. The CareNet Display is an interactive, ambient picture frame similar to Elizabeth Mynatt and colleagues' Digital Family Portrait. ${ }^{4}$ The CareNet Display provides local-network members with updates throughout the day about the elder's calendar and information about the elder including meals, medications, outings, activities, and mood.

To study how introducing a CSCC technology might affect support networks, we deployed CareNet Displays for three-week periods in the homes of two to three members from each of four support networks. We interviewed all participants, including the elders, before and after the three-week deployments. All participants except the elders completed midand poststudy questionnaires (other network members living in the same household as the study participants also completed questionnaires). Study participants were the four elders (aged 80-91) and nine support network members (aged 44-60).

Research team members collected the data used in the CareNet Display by calling the elders and their caregivers several times each day. The evaluators then immediately updated the displays remotely using a Web-based tool. We expect sensors would replace human evaluators in future versions of this type of technology.

\section{Results}

Our analyses of the interviews and technology probe studies explored how information systems can help the people who provide care while respecting the elder's concerns. In line with this goal, we discovered several common themes that help shape the CSCC perspective.

Care networks. Elders who live at home generally have rich care networks-support networks of people who provide the elder with care. These care networks include people of varying ages and computer skills who provide assistance ranging from day-to-day activities to social support. They consist of family members, friends, and often neighbors. Paid help such as professional caregivers, pharmacists, house cleaners, and doctors might also be involved. Although doctors 


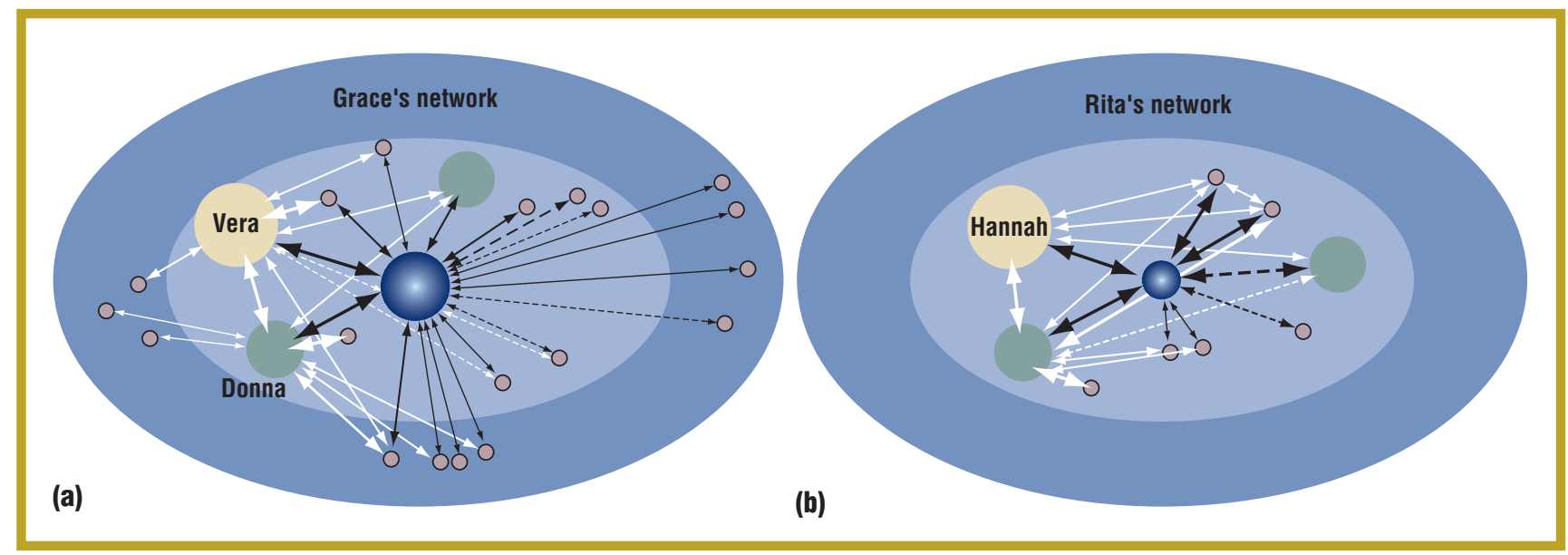

Figure 1. Care network diagrams for elders Grace and Rita. Circles represent network members. Ovals (light blue = near; dark blue $=$ far) indicate distance from the elder. Lines show communication flow (thickness represents volume). White lines represent communications about, but not directly with, the elder.

and other healthcare workers are important care network members, we did not interview them and thus do not include them in our analysis. We call the individuals who provide care network members. Network members might live with the elder, but might live in other states or even other countries. Local members tend to provide most of the care.

Complexity. The complexity of care networks varies. For example, 91-year-old Grace lives alone and has a care network of more than 20 members. Her two daughters and a close family friend provide most of her care. Several other relatives and friends also provide social support, home maintenance, and occasionally fill in for other members when they're unavailable. Grace also has a weekly house cleaner and an on-call handyman who have intermittent roles in her care network. When she is particularly ill, professional caregivers temporarily join her network. Another elder, Rita, lives alone and has a care network of 10 members. Rita's primary support comes from three of her four children and a part-time professional caregiver.

Figure 1 diagrams these two care networks. The circle in each diagram's center represents the elder. Other circles represent network members:
- Yellow-members who have made drastic life changes to care for the elder

- Green-members who significantly contribute to the elder's care

- Pink-members who have peripheral involvement in the elder's care

The size of the elder's circle reflects the amount of care she can provide for herself. The ovals show the physical distance of network members to the elder. The inner light blue oval represents members living within reasonable driving distance, and the outer dark blue oval represents members living much further away. Lines show communication flow, with thickness representing volume. Solid lines represent family relations, and dashed lines are for unrelated members. Black lines represent communications between the elder and other network members. White lines represent communications about, but not directly with, the elder. These diagrams show that network structures vary, but local members provide the majority of care.

Network members often have significantly different roles in the elder's care, and consequently their roles impact their lives differently. We separated network members into three categories according to the impact that providing care has on their lives:
- Those who make drastic life changes to support the elder

- Those who make significant contributions to care for the elder

- Those who have peripheral involvement in the elder's care

In each network we studied, one member drastically changed his or her life to care for the elder. Changes included quitting jobs and forgoing social activities such as hobbies and travel. For example, Rita's daughter Hannah works a parttime job with flexible hours. Although she likes bike riding, hiking, and participating in her book club, she often cannot do these activities because she must be available to help Rita. Grace's daughter, Vera, mentioned that she has "had to put her life on hold to care for [Grace]." Like Hannah, Vera works a part-time job with flexible hours. She has turned down job offers she otherwise would have taken because they did not allow enough flexibility with her schedule. She also seldom takes vacations. The members who have made drastic life changes to support the elder are critical network members; their sudden absence would have a strong, negative impact on the elder's care.

In each network, a few members make significant, regular contributions to the elder's care but have not had to drasti- 
cally change their lives to provide care. These members' lives have certainly been affected by the role of providing care, but they have not had to quit their jobs, for example; their primary focus is still their own daily lives.

Other members are peripherally involved. These members might have sporadic social or home maintenance-type interactions with the elder. For these

\section{Sharing information through}

\section{the CareNet Display alleviated \\ the dissemination task previously performed \\ by certain network members.}

members, caring for the elder has had minor impact on their lives, but the interactions with these members still hold meaning for the elder.

We also found that network members are often unclear about the amount of care other members provide for the elder. In general, the drastic life changers and the elder have an accurate understanding about the participation of each network member, but significant contributors tend to believe that they and drastic life changers contribute to the care "about equally." This misunderstanding often leads to tension in the network. CSCC systems can increase awareness of all members' participation levels. About the CareNet Display's feature of sharing information among network members, one significant contributor claimed, "[We] all benefit with this system of sharing the responsibility."

Information dissemination. Not surprisingly, phone calls and face-to-face conversations are the primary forms of communication for care networks. In most care networks, a small number of members also use email. Despite email's many advantages, it cannot currently be used
For example, one of Grace's grandsons, who is in his 30s and works in construction, is a peripherally involved member in her network. Previously, he tried email for personal use, didn't like it, and decided he wouldn't use it again.

Because of the difficulties involved in communicating with network members, some members we observed aren't regularly informed about the elder's current condition. Rather, only a select few who talk with or see each other frequently know about the most recent occurrences. Several care networks developed systems that keep important information in a place that is known and accessible to local network members in the event of an emergency. For example, Vera helps Grace maintain a tote bag full of the important information a doctor or emergency medical technician might need; this bag is kept near the front door of Grace's house. Hannah has a similar file prepared for Rita. Other networks keep a shared notebook, similar to a guest book, at the elder's home. Anytime a member visits the elder, the member makes a note in the book and can read what has happened since the last visit.

In most cases, the CareNet Display deployment increased communication between network members and the elder. These increases centered on information gathered about the elder and shared with display users. For example, one peripherally involved member used the display to learn details about the elder's day-today life that he never knew before. He enjoyed learning these details and could speak with the elder about meaningful events from her daily routine. As a result, he became more involved in her care.

Sharing information through the CareNet Display also alleviated the dissemination task previously performed by certain network members. For example, the number of communications one significant contributor had with the network's drastic life changer decreased during the deployment. Through the display, the member got information about how often the elder was getting out of the house and who needed to drive her to appointments, eliminating the need for some phone conversations. Both parties welcomed the decrease in phone call frequency.

\section{Evolving needs of elders and network} members. Several network members mentioned the problem of keeping everyone on the same page- that is, having discussions about the elder's needs or problems of coordinating care-related activities, including keeping network members informed of important developments in the elder's condition.

A common concern was that some network members had an unclear understanding of the type of care that the elder needed and was given. For example, Vera mentioned that when something happens to Grace, the significant contributors sometimes don't understand how much care Grace requires. Recently when Grace was ill, Vera temporarily moved in with her to ensure she didn't develop a condition for which she is at risk. Several network members didn't think Vera needed 
to take such drastic measures. Vera felt they didn't understand the situation's seriousness and ignored her explanations, despite the fact that she is a registered nurse who specializes in geriatrics.

Problems can also occur when the elder resists additional help. For example, Rita has mild dementia. Her son has called to remind her to take her medication and waited on the phone while she claimed to ingest it, only to later learn that she did not. Rita has also told network members that she ate a "proper breakfast," when she only had a cup of coffee. Other network members are concerned about this, as a cup of coffee is not an acceptable breakfast for a diabetic like Rita. Unfortunately, Rita is unaware that she does not reliably communicate to the other members about significant events such as medication and breakfast. These unreliable reports have created issues when the network has tried to get Rita more help. Rita does not understand why she needs it, claiming she "is not a baby."

Care requirements for elders change over time. Some are predictable, such as the well-understood progressions of diseases and conditions. Others are unpredictable, brought on by sudden changes such as a fall, stroke, or virus. Such events can immediately change the care network's needs and dynamics. In Rita's case, her dementia impacts her ability to care for herself. Consequently, her children are becoming more insistent about her having around-the-clock care. Rita recently agreed to a two-hour-per-day professional caregiver. Her network hopes to move Rita to a larger apartment that could accommodate a live-in caregiver.

Although we observed few, if any changes in care needs during the technology probe's three-week deployments, it is flexible enough to accommodate such requirements. For example, it could monitor different types of information about the elder as needed. Most participants mentioned during their interviews that they anticipated their information needs would change over time.

\section{CSCC characteristics}

Based in part on the evidence collected in the interviews and from the technology probes, we determined that care network members have a strong need for tools that help coordinate the activities of the elder's care. This led us to define for the elder, or that all members have the same access to the elder and to her healthcare concerns.

Networks are created ad hoc, largely based on opportunity. For example, once when Grace was sick and no one else was available, her daughter Donna's tenant-who is usually involved at a peripheral level—stayed overnight with her. Each care network creates its own struc-

\section{A goal of CSCC technologies is to help the elder}

\section{remain as independent as possible, while letting}

\section{other network members maintain their}

$$
\text { day-to-day lives as a primary activity. }
$$

three characteristics that help distinguish CSCC from the broader research issues of CSCW and provide a scope within which researchers can focus their efforts.

\section{The focus is a person}

Because the care network's focus is a person, issues of emotion, trust, and privacy are primary. What is right for the elder from a health perspective is not necessarily right for the elder emotionally.

A further complication is the elder's dual role as both the network's focus and a network member. The network makes decisions about the type of care the elder can provide for him- or herself. Elders might be reluctant to admit the need for help with personal tasks such as bathing or paying bills.

\section{Organizational structure varies}

Relationships and coordination with network members are loosely coupled and often channeled through a central or designated member. You cannot assume that all network members know each other, that any member will take on any amount of responsibility, that members' skills are the same, that all members share the same motivation to care ture that might have to change as network members or the elder's needs and priorities change. Because no formal structure or organization for the related activities and members exist, the issue isn't so much collaboration or cooperation as it is coordination of the activities related to the elder's care.

\section{Caring is a background activity}

The interactions and activities related to caring for the elder are often secondary to care network members' primary work and play. A goal of CSCC technologies is thus to help the elder remain as independent as possible, while letting other network members maintain their day-to-day lives as a primary activity. CSCC systems that distribute responsibility could help some of the members who've made drastic life changes get some time back for themselves. For example, Rita's son only checks email one day a week and doesn't check voicemail in the evening, even though Hannah uses these methods to communicate with him about Rita. It's not that he doesn't care about his mother, but that he relies on Hannah to monitor Rita's immediate needs. Whereas he can maintain his day- 
to-day life as a primary activity, Hannah cannot do the same for hers.

\section{CSCC design guidelines}

Various CSCC systems could help the members of an elder's care network. Based on our user study results, we offer some design guidelines to help inform the development of successful CSCC systems. Although these guidelines are not unique to CSCC, they are particularly important for eldercare.

- Privacy for all care network members is crucial.

- CSCC systems should reduce cognitive load by augmenting current tasks rather than creating new tasks or by using the user's peripheral (or ambient) awareness.

- To minimize issues of trust and reliability of reporting, CSCC systems should employ redundancy in sensing, data collection, and sharing when appropriate.

CSCC systems should respect the privacy of the elder and other network members. For example, as a result of providing updates about the elder, the CareNet Display also shares and archives information about other network members (for example, Vera is driving Grace to Monday's appointment with Dr. Smith). We therefore involved a variety of network members in our design and evaluation to ensure that they were comfortable with including such information. Also, it was critical to the elders and other network members that the elder have a way to "not share" any event and to control which members saw which types of information.

Similar to awareness and instant messaging in CSCW, network members' attention to care-related activities is often peripheral to other tasks. CSCC solutions should attempt to reduce cognitive load and should fit into network mem- bers' current practices. Augmenting peoples' existing practices will be more successful if the solutions exploit existing technologies such as phones and televisions. Taking advantage of the user's periphery might also be appropriate, for example, with the use of ambient displays. The CareNet Display technology probe successfully used an ambient display form factor.

Often the elder and one or two network members collect data about the elder that they subsequently share. This practice can lead to human error. Network members often consider information reported by elders to be unreliable, usually due to issues of cognitive decline or embarrassment. High stress levels and lack of time are common issues for drastic life changers and contribute to inconsistencies with or omissions of critical data being shared. Results from the CareNet Display deployment suggest that data collected by a reliable third party (for example, a pervasive computing system) can solve such problems. For example, a member of one elder's network was surprised to see that her mother always had a glass of wine with dinner because her mother never mentioned it to her. Although the member had no intention of confronting her mother, she was relieved to know about it so she could alert relevant medical personnel in the event of an emergency.

\section{Employing pervasive computing}

Many opportunities exist for employing pervasive computing solutions in successful CSCC systems. Data collection is one such opportunity. Network members need timely and reliable information to provide an elder with care. For example, which medications has Mom taken today? Does Mom need a ride to her doctor appointment? Who will replace the burned-out light bulb in Mom's foyer? What activities did Mom do today? Pervasive computing technologies, such as environmental sensors, could become the network's data collectors. Assuming the sensors are sufficiently reliable, they could augment or replace current data collection tasks.

Recent advances in wireless sensor network technologies have resulted in drastic improvements in sensor size, cost, power usage, and variety. The latest generation of University of California, Berkeley, sensor motes ${ }^{5}$ is about the size of a US quarter and can report environmental conditions such as temperature, light, vibration, motion, and pressure for months at a time before needing a new battery. Wireless reporting and ad hoc routing make these platforms ideal for incremental deployment in existing homes. As wireless sensor networks move into mainstream production, they'll greatly enhance the quality and quantity of data that can be generated automatically and unobtrusively. New machinelearning techniques could monitor the care network's health; for example, by looking for vacated roles, uneven distribution of responsibility, or necessary but unavailable skills.

Another opportunity for CSCC research in the pervasive computing community is in context-aware communication. ${ }^{6}$ For example, others have suggested how you can use context-aware computing to coordinate exercise between elders living near each other. ${ }^{7}$ The same idea could be applied in CSCC care networks to help member-to-member and elder-tomember communications.

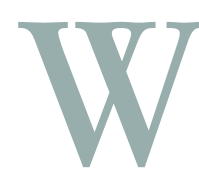
ork in CSCC could go in various directions. For example, sensors could be deployed in the home to gauge reactions to and acceptance of these new technologies or explore devices other than ambient, interactive picture frames. (Results from our CareNet 
Display deployments indicate that network members would prefer both an unobtrusive technology to use at home, such as the ambient, interactive picture frame, and a more mobile form factor, such as a phone service or Web site.) New machine-learning techniques could be used to monitor the care network's health. We also suspect that the CSCC approach could be broadened to address other groups of people who require regular care.

CSCC systems aim to improve the quality of care and life for all care network members, including the elder; they are not trying to remove people from the situation. The need for technologies to help care for elders is growing as the elderly population increases. Accordingly, the role and needs of care networks will also grow. More people in these care networks, including the elderly, will benefit from technology that helps target coordination activities, providing proper care for those who need it while letting care network members maintain their daily lives. $\mathbf{P}$

\section{ACKNOWLEDGMENTS}

The following people contributed to this research: Jeff Towle, Lenny Lim, Morgan Ames, Carol Johnston, Asuman Kiyak, Linda Reeder, Sandy Sabersky, Karen Sisson, Jay Lundell, Brad Needham, Margie Morris, Eric Dishman, Batya Friedman, Ken Fishkin, Miriam Walker, Richard Beckwith, Scott Lederer, Gaetano Borriello, Jimmi Montgomery, Christine Riley, James Landay, and Steve Gribble.

\section{REFERENCES}

1. D. Wan, "Magic Medicine Cabinet: A Situated Portal for Healthcare," Proc. Int'l Symp. Handheld and Ubiquitous Computing, LNCS 1707, Springer-Verlag, 1999.

2. J. Barddram, "Designing for the Dynamics of Cooperative Work Activities," Proc. ACM Conf. Computer Supported Cooperative Work (CSCW), ACM Press, 1998, pp. 89-98.

3. P. Roessler, S. Consolvo, and B. Shelton,

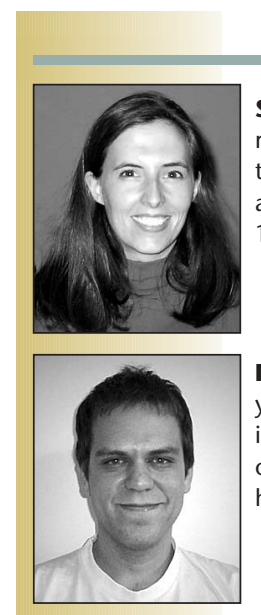

the AUTHORS

Sunny Consolvo is a member of the research staff at Intel Research Seattle. Her research focus is applying human-centered design to ubiquitous computing applications. She is currently working in the areas of location-aware computing and human activity inferencing. She is a member of the ACM and ACM SigCHI. Contact her at 1100 NE 45th St, 6th Floor, Seattle, WA 98105; sunny.consolvo@intel.com.

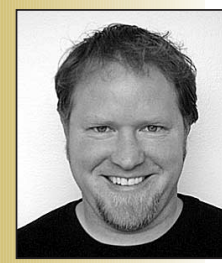

Brett E. Shelton is an assistant professor in the Department of Instructional Technology at Utah State University. His research interests include immersive learning environments and vision-related cognitive studies. He received a PhD in educational technology from the University of Washington. He is a member of the International Society of the Learning Sciences and the American Educational Research Association. Contact him at the Dept. of Instructional Technology, 2830 Old Main Hill, Logan, UT 84322-2830; bshelton@intel-research.net.

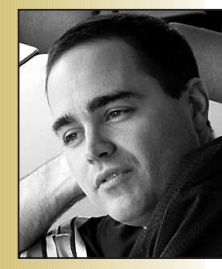

Anthony LaMarca is a member of the research staff at Intel Research Seattle. His research interests include location technologies, ubiquitous computing, distributed systems, and human-centered design, and he is currently working on a project to enable wide-scale device positioning using Wi-Fi base stations. He has a PhD in computer science from the University of Washington. Contact him at 1100 NE 45th St, 6th Floor, Seattle, WA 98105; anthony.g.lamarca@intel.com.

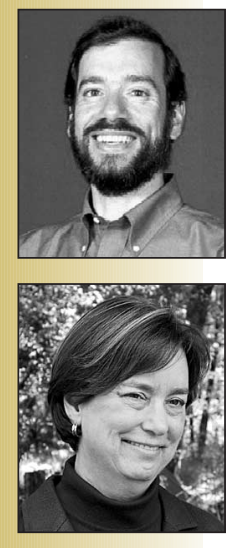

Phase \#1 of Computer-Supported Coordinated Care Project, tech. report IRS-TR-04005, Intel Research Lab, 2004.

4. E.D. Mynatt et al., "Digital Family Portraits: Supporting Peace of Mind for Extended Family Members," Proc. Conf. Human Factors in Computing Systems, ACM Press, 2001, pp. 333-340.

5. J. Hill et al., "System Architecture Directions for Networked Sensors," Proc. Architectural Support for Programming Languages and Operating Systems, ACM Press, 2000, pp. 93-104.
6. B.N. Schilit, D.M. Hilbert, and J. Trevor, "Context-Aware Communication," IEEE Wireless Comm., vol. 9, no. 5, Oct. 2002, pp. 46-54.

7. M. Morris et al., "New Perspectives on Ubiquitous Computing from Ethnographic Study of Elders with Cognitive Decline," Proc. 5th Int'l Conf. Ubiquitous Computing (UbiComp 2003), Springer-Verlag, 2003, pp. 227-241.

For more information on this or any other computing topic, see our Digital Library at www.computer/org/publications/dlib. 